\title{
MANUFAKTUR ALAT BANTU TANGKAP IKAN TIPE HIDROLIK UNTUK KAPAL KAPASITAS 5-10 GT
}

\author{
Manufacturing of Fishing Deck Machinery Hydraulic Type for 5-10 GT Ship \\ Capacity
}

\author{
Rudiansyah $^{1 *}$ dan A. Suwandi ${ }^{1}$ \\ ${ }^{1}$ Program Studi Teknik Mesin, Fakultas Teknik, Universitas Pancasila, Srengseng Sawah Jagakarsa Jakarta, \\ Indonesia
}

Informasi artikel

Diterima: $28 / 12 / 2019$ Direvisi : 05/01/2020 Disetujui: 23/01/2020

\begin{abstract}
Abstrak
Indonesia merupakan salah satu negara kepulauan. Namun faktanya, masih banyak nelayan yang hidup dalam garis kemiskinan karena ketidak mampuan para nelayan untuk menangkap ikan semaksimal mungkin. Untuk memecah permasalahan tersebut, diperlukan sebuah alat bantu tangkap ikan, alat ini merupakan alat yang digunakan untuk membantu mempermudah para nelayan menangkap ikan. Berdasarkan 51 proses manufaktur alat bantu tangkap ikan, komponen penyusun alat terdiri atas base, support base, rangka bawah, rangka atas, rangka sliding, hidrolik, bracket, pin dan motor penggerak. Dari hasil analisis DFMA, total waktu yang dibutuhkan untuk membuat alat bantu tangkap ikan yaitu 1397 menit. Adapun total biaya yang dibutuhkan untuk membuat 1 set alat bantu tangkap ikan adalah sebesar Rp 9.950.000, -.
\end{abstract}

Kata Kunci: fishing deck machinery, tipe hidrolik, manufaktur, produksi lokal.

\begin{abstract}
Indonesia is an archipelago; there are still many fishermen who live in the poverty line because of the inability of fishers to catch fish as much as possible. To solve this problem, we need fishing gear, and this fishing deck machinery is a tool used to help facilitate the fishermen catching fish. Based on 51 fishing gear manufacturing processes, the components of the machine comprise the base, support base, bottom frame, top frame, sliding frame, hydraulic, bracket, pin and drive motor. From the results of the DFMA analysis, the total time needed to make fishing aids is 1397 minutes. The total cost required to make 1 set of fishing gear is IDR 9,950,000,--
\end{abstract}

Keywords: fishing deck machinery, hydraulic type, manufacturing, local production. 


\section{PENDAHULUAN}

Negara Indonesia merupakan salah satu negara maritim di dunia, yang memiliki banyak pulau-pulau besar dan kecil yang jumlahnya kurang lebih 17.508 pulau. Sesuai catatan bahwa tiga perempat luas dari wilayah Indonesia adalah lautan, dengan total luas mencapai 5,8 juta $\mathrm{km} 2$, dan garis pantai sepanjang $81.290 \mathrm{~km}$ (KKD, 2015). Hal ini menjadikan Indonesia sebagai negara kepulauan terbesar di dunia setelah kanada. Keberadaan perairan Indonesia yang sangat luas dan terletak di posisi silang antara dua samudra dan dua benua, mengharuskan Indonesia untuk menjalin kerja sama dan kesatuan di antara negara-negara tetangga, khususnya dalam bidang perikanan.

Dari fakta tersebut adalah suatu kewajaran jika nelayan selayaknya mendapat perhatian lebih dalam melakoni pekerjaannya. Namun berbagai upaya yang dilakukan pemerintah nyatanya hingga saat ini masih belum mampu sepenuhnya meningkatkan kesejahteraan para nelayan, terlebih nelayan kecil yang ada di wilayah pesisir dan pulau-pulau kecil. Salah satu faktor penyebab sulit terputusnya rantai kemiskinan di kalangan nelayan adalah tidak seimbangnya hasil tangkapan ikan dengan biaya operasional yang di keluarkan.

Untuk mengatasi permasalahan di atas, diperlukan sebuah kapal yang dilengkapi teknologi penangkap ikan yang lebih modern dibandingkan dengan kapal yang digunakan nelayan pada umumnya. Hal ini dimaksudkan agar membantu memudahkan nelayan untuk meningkatkan produktivitas hasil tangkapan ikan (Cahyadi dan Suwandi, 2017). Dengan begitu, biaya operasional tertutupi dan keuntungan bisa didapatkan.

Melatar belakangi kenyataan yang ada, maka perealisasian hasil rancangan yang sudah ada perlu dilakukan agar manfaatnya bisa langsung dirasakan oleh nelayan (Tanjung dan Suwandi, 2017), sehingga produktivitas ikan yang diperoleh nelayan dapat meningkat dan kesejahteraan hidup bisa tercapai.

Tujuan dari pembuatan alat bantu penangkap ikan tipe hidrolik adalah untuk membuat sistem penangkapan ikan yang lebih modern, sehingga membantu meningkatkan hasil tangkapan ikan nelayan. Dalam tulisan ini akan membahas tentang proses manufaktur dari alat bantu tangkap ikan, hingga perhitungan biaya produksi.

\section{METODOLOGI}

Secara umum menjelaskan tentang langkah yang dilakukan metode penelitian seperti yang dilakukan seperti di Gambar 1 .

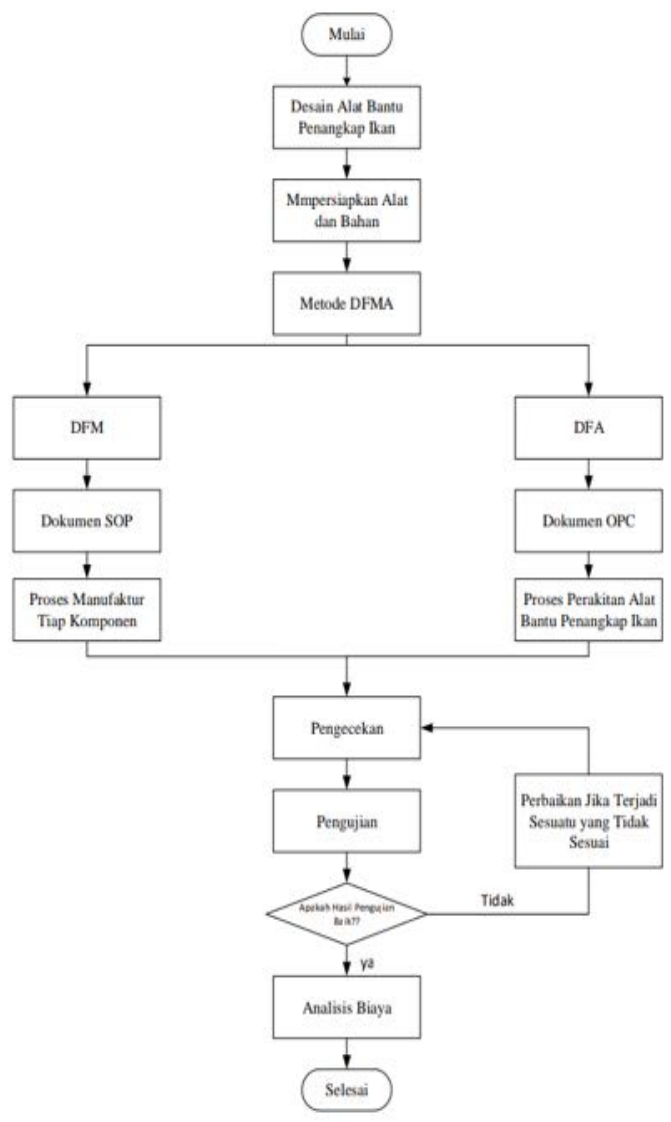

Gambar 1 Diagram alir penelitian

Berikut penjelasan dari tahapan yang dilakukan:

a. Desain alat bantu penangkap ikan

Desain produk ini didapat dari perancangan yang telah dilakukan sebelum melakukan pembuatan alat penagkap tersebut.

b. Persiapan alat dan bahan yang digunakan

Mempersiapkan alat dan juga bahan yang akan digunakan pada saat pembuatan alat bantu penangkap ikan guna memperlancar pada saat proses pembuatan alat penangkap tersebut.

c. DFMA (Design for manufacturing and assembly)

DFMA sendiri adalah metode yang terdiri dari penggabungan 2 metode yaitu DFM dan DFA. Metode DFM adalah metode yang membahas tentang proses manufaktur dari suatu alat atau komponen sedangkan DFA adalah metode yang membahas proses 
assembly dari alat atau komponen yang telah dibuat tadi. Dari proses DFM ada beberapa langkah pengerjaan yang akan dilakukan berdasarkan SOP (standart operation procedure) seperti Gambar 2.

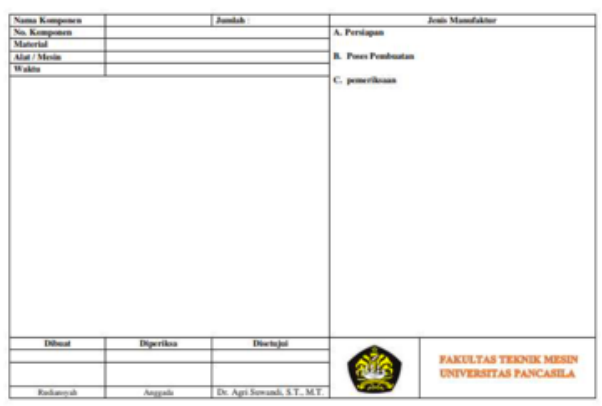

Gambar 2 Contoh lembar SOP

(Standart Operation Procedure)

SOP sendiri di buat agar mempermudah dan juga dapat menjelaskan bagaimana proses pembuatan untuk suatu komponen pada produk, dalam SOP sendiri terdapat detail proses yang akan di lakukan nantinya seperti proses dibawah adalah beberapa proses yang akan dilakukan berdasarkan SOP, yaitu :

1. Proses pengukuran, pada proses ini dilakukan pengukuran dan menandai bagian yang akan di potong.

2. Proses pemotongan, pada proses ini dilakukan proses pemotongan dengan gergaji manual ataupun gergaji mesin.

3. Proses pengeboran, pada proses ini dilakukan proses pengeboran dibagian tertentu yang akan diberi lubang

4. Proses pengelasan, pada proses ini dilakukan proses pengelasan dibagian tertentu yang akan di las

\section{HASIL DAN PEMBAHASAN}

\section{Proses Manufaktur}

Dari hasil rancangan ini selanjutnya akan masuk ke dalam proses pembuatan atau manufaktur. Desain rancangan alat bantu penangkap ikan dapat dilihat pada Gambar 3.

Berikut akan di jelaskan proses pembuatan komponen alat bantu penangkapan ikan yang terdiri dari: base, kelos, poros, serta tuas. Tahapan manufaktur yang dilakukan mengikuti tahapan dari SOP (Standard Operational Procedure) yang mengacu pada Operation Process Chart (OPC) seperti pada Gambar 4.

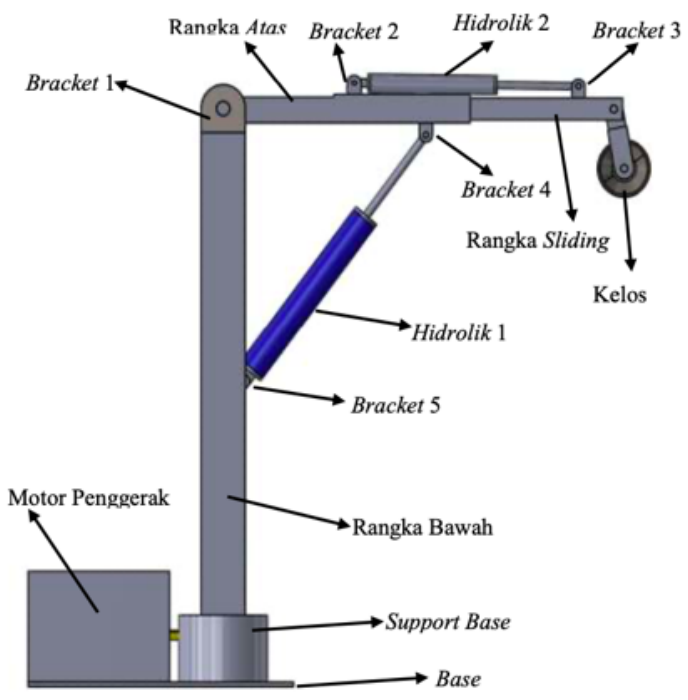

Gambar 3 Desain alat bantu tangkap ikan tipe hidrolik (Suwandi et al., 2018)

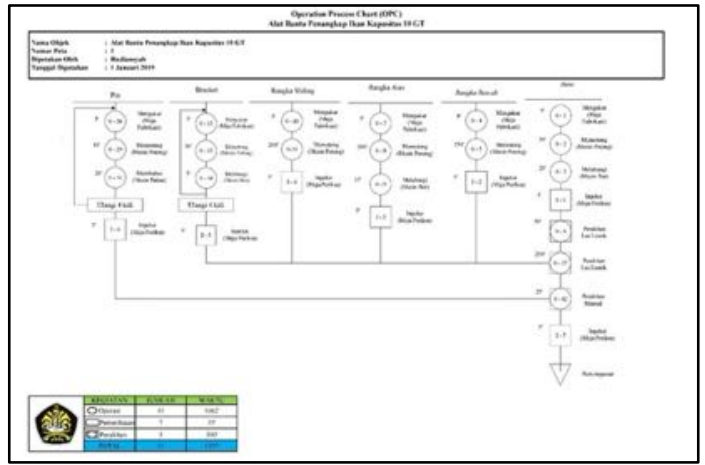

Gambar 4 Operation Process Chart (OPC)

Proses DFA (Design For Assembly) tujuannya adalah untuk menyederhanakan struktur produk agar proses perakitannya menjadi lebih singkat (Boothroyd, 2005). Sehingga waktu yang diperlukan untuk masing-masing proses perakitan dapat diketahui. Pada alat bantu penangkap ikan, jumlah komponen dapat dilihat pada Tabel 1 , yaitu terdiri atas 19 komponen dengan 9 jenis komponen yang berbeda-beda, antara lain: base,support base, rangka atas, rangka bawah, rangka sliding, hidrolik, bracket, pin dan motor penggerak.

Berdasarkan Tabel 2, dapat diketahui jumlah proses utama dari pembuatan alat bantu tangkap ikan adalah berjumlah 25 proses. Namun karena terdapat beberapa proses yang harus dilakukan secara berulangulang, maka total keseluruhan prosesnya adalah 53 proses. Selanjutnya, berdasarkan Tabel 2, juga dapat diketahui jumlah waktu yang dibutuhkan untuk membuat alat bantu 
tangkap ikan, yaitu total waktunya 1733 menit.

Tabel 1 Komponen alat bantu penangkap ikan

\begin{tabular}{|c|c|c|c|c|}
\hline No & Nama Komponen & Material & Jumlah & Keterangan \\
\hline 1 & Base & Besi Plat & 1 Buah & Dibuat \\
\hline 2 & Support Base & Besi Batang Bulat & 1 Buah & Dibuat \\
\hline 3 & Rangka Bawah & $\begin{array}{c}\text { Besi Profil H- } \\
\text { beam }\end{array}$ & 1 buah & Dibuat \\
\hline 4 & Rangka Atas & $\begin{array}{c}\text { Besi UNP / Kanal } \\
\text { U }\end{array}$ & 1 buah & Dibuat \\
\hline 5 & Rangka Sliding & $\begin{array}{c}\text { Besi UNP / Kanal } \\
\text { U }\end{array}$ & 1 buah & Dibuat \\
\hline 6 & Hidrolik & Besi Plat & 5 buah & Dibuat \\
\hline 7 & Bracket & Besi Batang Bulat & 5 buah & Dibuat \\
\hline 8 & Pin & 1 buah & Dibeli \\
\hline 9 & Motor Penggerak & & 1 buah & Dibeli \\
\hline 10 & Kelos & & & Dibeli \\
\hline
\end{tabular}

Tabel 2 DFA (Design For Assembly)

\begin{tabular}{|c|c|c|c|}
\hline No. & Deskripsi Proses & $\begin{array}{l}\text { Jumlah } \\
\text { Teoritis }\end{array}$ & $\begin{array}{l}\text { Waktu } \\
\text { (menit) }\end{array}$ \\
\hline 1 & Mengukur besi plat tebal $5 \mathrm{~mm}$ untuk pembuatan base bawah & $1 \mathrm{x}$ proses & 5 \\
\hline 2 & Memotong besi plat & $1 \mathrm{x}$ proses & 30 \\
\hline 3 & Melubangi plat base berdiameter $20 \mathrm{~mm}$ berjumlah 8 buah lubang & $1 \mathrm{x}$ proses & 20 \\
\hline 4 & Mengukur besi bulat bediameter untuk pembuatan support base & $1 \mathrm{x}$ proses & 5 \\
\hline 5 & Memotong besi bulat & $1 \mathrm{x}$ proses & 75 \\
\hline 6 & Memasang support base pada base bwah & $1 \mathrm{x}$ proses & 50 \\
\hline 7 & Mengukur material besi H-Beam untuk pembuatan rangka bawah & $1 \mathrm{x}$ proses & 8 \\
\hline 8 & Memotong besi H-Beam & $1 \mathrm{x}$ proses & 250 \\
\hline 9 & Mengukur besi UNP untuk pembuatan rangka atas & $1 \mathrm{x}$ proses & 5 \\
\hline 10 & Memotong besi UNP & $1 \mathrm{x}$ proses & 200 \\
\hline 11 & Melubangi besi UNP & $1 \mathrm{x}$ proses & 15 \\
\hline 12 & Mengukur besi UNP untuk pembuatan rangka sliding & $1 \mathrm{x}$ proses & 10 \\
\hline 13 & Memotong besi UNP & $1 \mathrm{x}$ proses & 200 \\
\hline 14 & Mengukur material plat besi $2 \mathrm{~mm}$ untuk pembuatan bracket & $5 x$ proses & 5 \\
\hline 15 & Memotong material plat besi & $5 x$ proses & 150 \\
\hline 16 & Melubangi material plat dengan diameter $30 \mathrm{~mm}$ & $1 \mathrm{x}$ proses & 5 \\
\hline 17 & Melubangi material plat dengan diameter $28 \mathrm{~mm}$ & $4 x$ proses & 20 \\
\hline 18 & Memasang bracket pada rangka atas dan rangka bawah & $5 x$ proses & 250 \\
\hline 19 & Mengukur besi bulat berdiameter untuk pembuatan pin & $1 \times$ proses & 5 \\
\hline 20 & Memotong besi bulat & $5 x$ proses & 45 \\
\hline 21 & Membubut besi bulat menjadi diameter $30 \mathrm{~mm}$ & $1 \mathrm{x}$ proses & 10 \\
\hline 22 & Membubut besi bulat menjadi diameter $28 \mathrm{~mm}$ & $4 \mathrm{x}$ proses & 120 \\
\hline 23 & Memasang pin pada rumah pin & $5 x$ proses & 100 \\
\hline 24 & Pemasangan hidrolik pada struktur alat & $2 x$ proses & 100 \\
\hline 25 & Pemasangan motor penggerak & $1 \mathrm{x}$ proses & 50 \\
\hline \multicolumn{2}{|r|}{ TOTAL } & 53 proses & 1733 \\
\hline
\end{tabular}

Untuk menganalisis proses manufaktur dan assembly, dapat mengacu pada daftar OPC (Operation Procedure Chart) yang telah dibuat (lihat lampiran OPC). Dengan melihat daftar OPC tersebut, dapat diketahui berapa banyak proses yang terjadi dan jumlah waktu yang diperlukan dalam pembuatan produk.

a) Proses Pembuatan Base.

Tahap pertama adalah mengukur dan membuat pola pada material plat dengan diameter $5 \mathrm{~mm}$ (lihat Gambar 5).

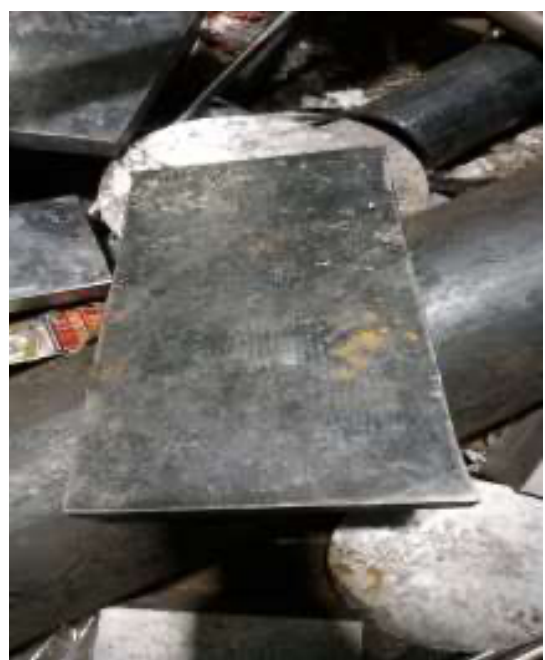

Gambar 5 Plat base

Mengukur material agar sesuai dengan ukuran yang ada pada desain setelahnya dilakukan proses untuk mengurangi ukuran plat dengan proses pengerjaannya adalah cutting blender, setelah di kurangi ukuran maka selanjutnya adalah pengecekan apakah pemotongan material sesuai dengan pola. Setelah pengecekan maka masuk ke proses pembuatan lubang untuk menempatkan baut dan mur.

b) Pembuatan Rangka Bawah

Besi profil H-Beam menjadi material yang dipilih untuk membuat rangka bawah dari alat bantu penangkap ikan. Jenis ukuran yang digunakan dari besi $H$ Beam adalah $6000 \mathrm{~mm}$. Proses pembuatannya menggunakan mesin gergaji potong, yaitu material ini dipotong dengan mesin potong menjadi ukuran dengan panjang $1600 \mathrm{~mm}$ seperti pada Gambar 6.

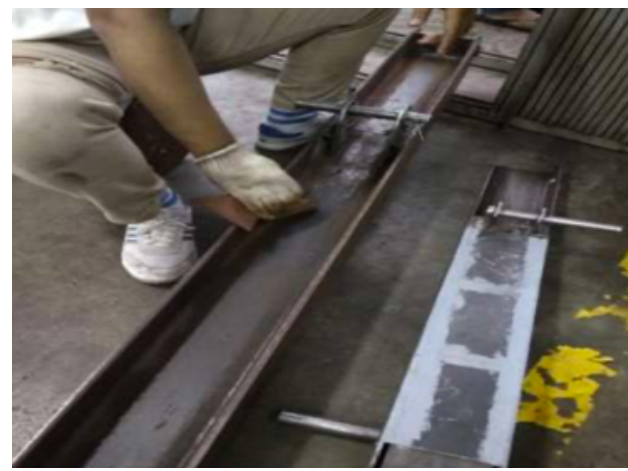

Gambar 6 H-beam untuk rangka bawah

c) Pembuatan Rangka Atas

Berbeda dengan rangka bawah, rangka atas alat bantu penangkap ikan menggunakan besi tipe UNP atau besi 
kanal U (lihat Gambar 7). Proses pembuatannya hanya pemotongan mengikuti panjang dari material.

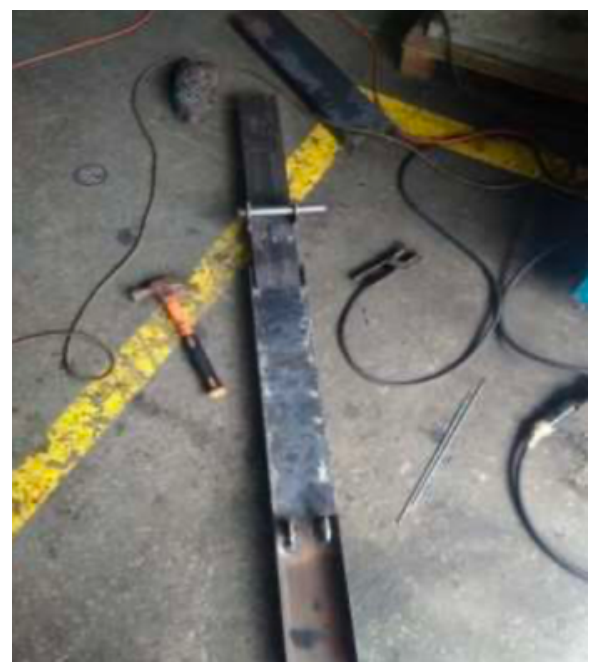

Gambar 7 H-beam untuk rangka bawah

d) Pembuatan Rangka Sliding

Jenis material yang digunakan untuk pembuatan rangka sliding adalah besi UNP, seperti halnya yang digunakan untuk rangka atas. Hanya saja, ukuran yang digunakan untuk rangka sliding lebih kecil dari ukuran rangka atas (lihat Gambar 8).

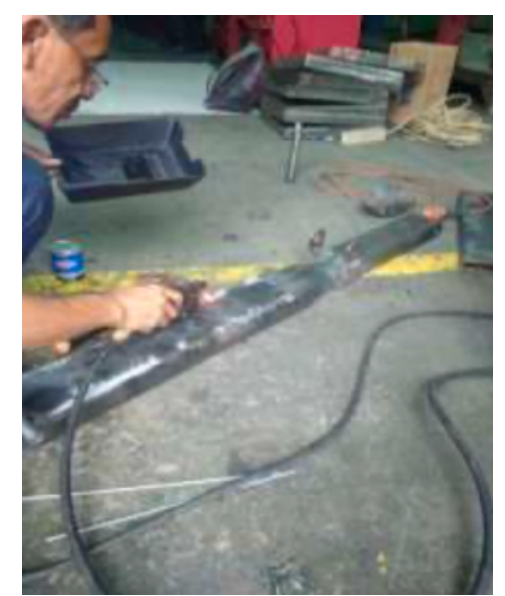

Gambar 8 Pembuatan rangka sliding

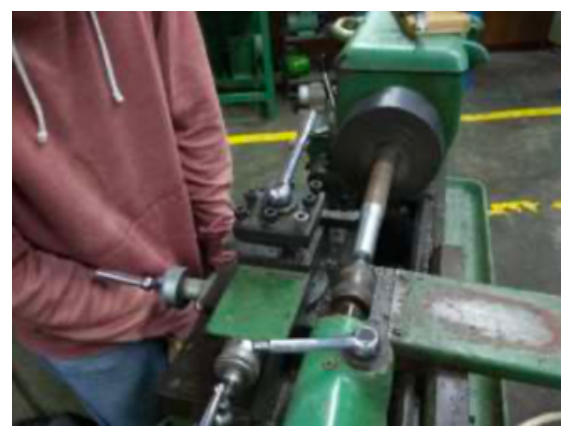

Gambar 9 Pembuatan pin e) Pembuatan Pin

Tahapan untuk pembuatan pin, dimulai dari pemotongan material mentah berupa batang bulat. Setelah dipotong, material tersebut kemudian ditipiskan diameternya menggunakan mesin bubut (lihat Gambar 9).

\section{Analisis Biaya}

Untuk dapat menentukan perkiraan harga jual dari alat bantu penangkap ikan tipe hidrolik ini maka di perlukan analisi perhitungan biaya produksi alat tersebut, yang terdiri dari biaya material. Harga bahan baku material alat bantu penangkap ikan tipe hidrolik berdasarkan kebutuhan material yang disajikan dalam Tabel 1.

Tabel 1 Biaya bahan baku

\begin{tabular}{clc}
\hline No & \multicolumn{1}{c}{ Material } & Harga (Rp) \\
\hline $\mathbf{1}$ & Besi H-Beam & Rp. 3.855.000,- \\
$\mathbf{2}$ & Besi UNP & Rp. 187.000,- \\
$\mathbf{3}$ & Besi Plat & Rp. 250.000,- \\
$\mathbf{4}$ & Besi Batang & Rp. 70.000,- \\
$\mathbf{5}$ & Elektroda nikko steel RD260 & Rp. 23.000,- \\
& 2.0mm, 1 pack = 40 buah & \\
$\mathbf{6}$ & Motor Listrik Ac 3 Phase & Rp. 3.000.000,- \\
$\mathbf{7}$ & Cat & Rp. 20.000,- \\
$\mathbf{8}$ & Mur Dan Baut M 20 10 Pasang & Rp. 30.000,- \\
$\mathbf{9}$ & Kelos $\quad$ Total & Rp. 1.200.000,- \\
& & Rp 8.635.000,- \\
\hline
\end{tabular}

Perkiraan biaya produksi dapat ditentukan dengan perhitungan yang mencangkup perkiraan biaya tenanga kerja langsung dan biaya overhead produksi yang di sajikan pada Tabel 2. Sedangkan perencanan laba produksi dapat di hitung dengan asumsi laba $10 \%$ dari biaya keseluruhan yang disajikan pada Tabel 3 .

Tabel 2 Biaya produksi 1 set alat bantu penangkap ikan

\begin{tabular}{|c|c|c|c|}
\hline No & Komponen & Quantity & $\begin{array}{c}\text { Total Biaya Tenaga Kerja } \\
\text { Langsung (Rp) }\end{array}$ \\
\hline 1 & Pin & 5 buah & Rp. $100.000,-$ \\
\hline 2 & H-Beam & 1 buah & Rp. $75.000,-$ \\
\hline 3 & UNP / Kanal U & 2 buah & Rp. $155.000,-$ \\
\hline 4 & Base & 1 buah & Rp. $175.000,-$ \\
\hline 5 & Bracket & 8 buah & Rp. 35.000,- \\
\hline \multicolumn{3}{|c|}{ Total } & Rp 540.000.- \\
\hline
\end{tabular}

Tabel 3 Perkiraan harga alat bantu penangkap

\begin{tabular}{|c|c|c|}
\hline$\underline{\underline{N_{0}}}$ & Jenis Biaya & Jumlah (Rp) \\
\hline$\underline{1}$ & Biaya Total Bahan Baku & Rp 8.635.000,- \\
\hline$\underline{2}$ & Biaya Produksi & Rp $540.000 .-$ \\
\hline$\underline{3}$ & Laba yang Dikehendaki $10 \%$ & Rp. 775.000 ,- \\
\hline & Total & Rp 9.950.000,- \\
\hline
\end{tabular}


Berdasarkan Tabel 3, maka perkiraan harga alat bantu penangkap ikan yaitu sebesar Rp 9.950.000,- per set (Sembilan Juta Sembilan Ratus Lima Puluh Ribu Rupiah).

\section{SIMPULAN}

Alat yang dirancang merupakan alat bantu penangkap ikan yang diperuntukkan untuk kapal 10 GT menggunakan tenaga hidrolik. alat bantu penangkap ikan terdiri atas 19 komponen dengan 9 jenis komponen yang berbeda-beda, antara lain: base, rangka atas, rangka bawah, rangka sliding, hidrolik, bracket, pin dan motor penggerak. Dapat diketahui ada 51 proses utama dari pembuatan alat bantu tangkap ikan yaitu total waktunya 1379 menit. Biaya bahan baku 1 set alat bantu penangkap ikan sebesar Rp 8.635.000,-. Biaya produksi sebesar Rp. 540.000 , - Dan biaya perencanaan keuntungan sebesar Rp. 775.000,-. Sehingga taksiran penjualan harga satu set alat bantu penangkap ikan adalah sebesar $\mathrm{Rp}$ 9.950.000,-.

\section{DAFTAR PUSTAKA}

Cahyadi R, Suwandi A, Perancangan alat bantu penangkap ikan (Fishing Deck Machinery) untuk peningkatan produktivitas nelayan, Jurusan Teknik Mesin Universitas Pancasila, Jakarta, Vol 16, No 2,2017

G. Boothroyd, Assembly Automation and Product Design, London : Taylor \& Francis Group, 2005.

K.K.D. Perikanan, "Program Kajian Stok Ikan Nasional," Kementrian Kelautan Dan Perikanan, Jakarta, 2015. B

Suwandi A., Anggada, D. L. Zariatin, B. Sulaksono, dan E. Prayogi, "Perancangan Konsep Alat Bantu Penangkapan Ikan ( Fishing Deck Machinery ) Tipe Hidrolik untuk Kapal > 5 GT," Seminar Rekayasa Universitas Pancasila, pp. 313-319, 2018.

Tanjung A. dan A. Suwandi, "Manufaktur Alat Bantu Penangkap Ikan (Fishing Deck Machinery) Produksi dalam Negeri," Seminar Nasional Sains Dan Teknoogi Universitas Muhammadiyah Jakarta, no. November, pp. 1-2, 2017. 